\title{
Rajakarjalaisen sukunimistön kehittyminen osana Suomen karjalankielisen ortodoksivähemmistön suomalaistumista $1818-1925$
}

\author{
Outi Patronen
}

\section{Väitöksenalkajaisesitelmä Helsingin yliopistossa 30. lokakuuta 2017}

Laatokan koillispuolella sijainneeseen Raja-Karjalaan kuului kuusi pitäjä: Suojärvi, Korpiselkä, Soanlahti, Suistamo, Impilahti ja Salmi. Alueella ei ollut kaupunkeja, mutta Sortavala sijaitsi lähellä. Raja-Karjala oli historiallisesti ja kulttuurisesti hyvin yhtenäinen alue. Enemmistö sen asukkaista tunnusti ortodoksista uskontoa ja oli äidinkieleltään karjalankielisiä, joko varsinaiskarjalan murteen tai livvin murteen puhujia. Raja-Karjalan eri osien keskinäiset kulttuurierot liittyivät muun muassa luterilaisen eli suomenkielisen väestön osuuteen pitäjässä. Luterilaisia asui alueen länsiosissa enemmän kuin muualla Raja-Karjalassa. Ennen talvisodan syttymistä Raja-Karjalassa oli noin 50 ooo asukasta.

Raja-Karjalaan ja siellä vallinneeseen ortodoksis-karjalaiseen kulttuuriin on vaikuttanut sijainti kahden valtakunnan, Ruotsin ja Venäjän, välissä. Autonomian ajalla RajaKarjalan ortodoksit olivat hallinnollisesti Ruotsi-Suomen kansalaisia mutta hengellisessä mielessä Venäjän ortodoksisen kirkon alamaisia. Ennen kuin itäraja vuonna 1918 suljettiin, rajakarjalaisilla, erityisesti suojärveläisillä ja salmilaisilla, oli tiiviit ja monipuoliset yhteydet itään Aunuksen Karjalaan. Rajakarjalaiset ja aunuksenkarjalaiset olivat karjalankielisiä ortodokseja, joilla oli keskenään muun muassa kauppa- ja sukulaisuussuhteita.

Ortodoksis-karjalainen kulttuuri tuli esiin päivittäin arjessa ja yhteiskunnallisessa elämässä sekä riiteissä. Kulttuuriin kuului esimerkiksi ristinmerkin tekeminen arjen eri tilanteissa, paastoaminen ennen tiettyjä juhlapyhiä ja praasniekkojen viettäminen. Praasniekat ovat ortodoksisia juhlapyhiä, joita vietetään kylän pyhäkön, kirkon tai tsasounan eli rukoushuoneen, kunniaksi. Ortodoksiset kalmistot eli hautausmaat, kirkot 
ja tsasounat kuuluivat kiinteästi Raja-Karjalan kulttuurimaisemaan. Ennen talvisotaa alueella oli yli 60 tsasounaa ja 15 ortodoksista kirkkoa. (Raivo 1996: 76, 83; Kokkonen 2015: 16.)

Sen perusteella, että Raja-Karjalan ortodokseilla oli oma karjalais-ortodoksinen kulttuuri-identiteetti ja oma kieli, heitä voidaan pitää etnisenä vähemmistönä. Tätä mieltä ovat ne eri alojen tutkijat, jotka ovat tutkineet nimenomaan rajakarjalaisia (esim. Hämynen 2011: 204). Sen sijaan Suomen vähemmistöjä käsittelevissä tutkimuksissa ortodoksikarjalaisia ei luokitella etniseksi vähemmistöksi.

Tutkimuksessani olen selvittänyt, millä tavoin ja milloin Raja-Karjala ja sen asukkaat alkoivat suomalaistua ja miten aluetta ja sen asukkaita suomalaistettiin. Sen jälkeen, kun kareliaanit eli kansanrunouden tutkijat ja eri alojen taiteilijat olivat löytäneet Raja-Karjalan, Sortavalaan perustettiin vuonna 1880 opettajaseminaari. Seminaarin tarkoitus oli kouluttaa opettajia Raja-Karjalaan: rajaseudulla asunut ortodoksiväestö haluttiin suomalaisen kansakoulun avulla sitoa tiiviisti muuhun Suomeen. Nimenomaan suomalaista kansakoulua on pidetty yhtenä syynä Raja-Karjalan suomalaistumiseen. Kansakoulun myötä suomen kieli valtasi alaa karjalan kieleltä, ja koulu ohjasi rajakarjalaisten maalaiskylien elämänrytmiä suomalaisemmaksi. (Hämynen 2011: 205.)

Rajakarjalainen kulttuuri-identiteetti alkoi muuttua 1800-luvun lopulla ja 1900-luvun alussa. Ne rajakarjalaiset, jotka olivat paljon tekemisissä muualta Suomesta tulleiden virkamiesten ja muiden, työnsä puolesta alueella oleskelleiden tai liikkuneiden kanssa, saivat jo varhain läntisiä eli suomalaisia vaikutteita. Tutkimuksessani pohdin, keitä nämä niin sanotut kulttuurin välittäjät eli kulttuuriin johdattelijat ovat olleet. (Kulttuurin välittäjistä ks. Lehtola 2012: 20.)

Vuosi 1918 merkitsi Raja-Karjalan väestölle kriisiä: elintärkeä yhteys Aunuksen Karjalaan katkesi, ja katseet piti kääntää idästä länteen, muun Suomen suuntaan. Pian Suomen itsenäistymisen jälkeen huomattiin, että rajakarjalainen kulttuuri oli alkanut sulautua suomalaiseen kulttuuriin. Omaperäinen kansanperinne ei enää siirtynyt sukupolvelta toiselle, ja rajakarjalainen rakennusperinne oli katoamassa. (Esim. Makkonen 1989: 167; Lampén 1922: 49, 68-70.) Maantieverkoston kehittämisen ja Suojärven-radan rakentamisen (1922) myötä suomalaisia vaikutteita saatiin entistä enemmän.

Tutkimuksessani olen tarkastellut myös sitä, millainen asema puhutulla ja kirjoitetulla karjalan kielellä oli Raja-Karjalassa ja miten asema muuttui. Karjalan kielen asema liittyy myös siihen, miten karjalankielisiin sukunimiin on suhtauduttu.

Karjalan kielen tutkijat ovat olleet jo tutkimuksen alkuvaiheista yhtä mieltä siitä, että karjala on oma kielensä, yksi suomen sukukielistä (Leskinen 1931: 8; Jeskanen 2005: 268). Sen sijaan muut kuin kielitieteilijät ovat Suomessa pitkään puhuneet siitä muun muassa karjalan murteena. Karjalaa on pidetty suomen kielen murteena, koska yhteinen kieli oli tärkeä perustelu sille, miksi Itä-Karjalan asukkaita pidettiin saman kansan jäseninä. (E. V. Ahtian aineisto, laatikko 12; Jeskanen 2005: 267-269.)

Karjalan kieli eli Raja-Karjalassa talvisotaan saakka kotikielenä ja kyläyhteisön kielenä, mutta käytännössä moni rajakarjalainen oli kaksikielinen (esim. Hämynen 2011: 205). Suomen kielen asema oli Raja-Karjalassa erittäin vahva: se oli muun muassa 
kansakoulun, lehdistön, kirjallisuuden, radion sekä hallinnon kieli. Vuodesta 1923 alkaen se oli myös Suomen ortodoksisen kirkon kieli.

Rajakarjalaisten kielenvaihto karjalasta suomeen alkoi vähitellen ja eteni eri tahtiin eri alueilla. Koska myös rajakarjalaiset pitivät puhumaansa kielimuotoa suomen kielen murteena, he eivät itse nostaneet omaa kieltään esiin. Heillä ei myöskään ollut omaa yhdistystä, joka olisi ajanut heidän kielensä ja kulttuurinsa asiaa; omakielinen kirjallisuus ei ehtinyt vielä syntyä. Raja-Karjalan ortodoksiväestön tilannetta voi hyvin verrata esimerkiksi kolttasaamelaisten tilanteeseen. 1900-luvun alkupuolella saamen kielellä ei ollut virallista asemaa, eikä se ollut kirkon virallisesti käyttämä kieli tai kouluopetuksen kieli. Näkemys, että karjala oli yksi suomen kielen lukuisista murteista, johti siihen, että sen kirjallisen käytön ajateltiin olevan hyvin rajallista. Kuitenkin esimerkiksi "Salmin murteella" kirjoitettujen lehtipakinoiden ajateltiin olevan arvokas osa rajakarjalaisen perinteen säilyttämistä. Sen sijaan suomalainen kielentutkija E. V. Ahtia, joka yritti luoda karjalan kielen eri murteille yhteisen kirjakielen, ei saanut näkemyksilleen eikä hankkeelleen tukea. (SKS KIA: Ahtia.)

Tutkimukseni sukunimiaineisto, jonka olen koonnut Viipurin läänin vuosien 18181925 henkikirjoista, käsittää 2357 sukunimeä. Kyseiset sukunimet ovat kuuluneet RajaKarjalan ortodoksiväestölle. Raja-Karjalan henkikirjoihin sukunimiä on alettu kirjata keskimäärin samoihin aikoihin kuin ortodoksisten seurakuntien asiakirjoihin.

Ennen vuotta 1880 vain pienellä osalla Raja-Karjalan ortodoksiväestöstä oli periytyvä sukunimi. Sukunimi oli muun muassa ortodoksisen kirkon papeilla ja muilla kirkonpalvelijoilla, ammattimiehillä ja hyvässä asemassa olleilla talonpojilla. Sen sijaan rajakarjalaisissa maalaiskylissä elänyt tavallinen väestö ei tarvinnut sukunimiä: riitti, että asiakirjoihin merkittiin perheenpään ristimänimi ja patronyymi eli isän nimeen perustuva nimi. Muista perheenjäsenistä kirjattiin usein vain ristimänimi.

Olen tutkimuksessani pyrkinyt selvittämään, miten se, että Raja-Karjalan ennestään sukunimettömälle ortodoksiväestölle alettiin kirjata sukunimiä, liittyy Raja-Karjalan historiallisiin tapahtumiin. Yksi syy siihen, miksi sukunimiä on alettu kirjata, näyttää olleen suomalaisen kansakoulun perustaminen kylään. Esimerkiksi Salmin Manssilan asukkaille sukunimiä kirjattiin erityisen tarmokkaasti vuosien 1890 ja 1895 välillä. Juuri noina vuosina kylään perustettiin kansakoulu. Kansakoulun perustaminen ei silti ole kaikkialla merkinnyt sitä, että ortodoksiväestön enemmistölle olisi alettu merkitä sukunimiä: Suistamon Leppäsyrjään avattiin kansakoulu vuonna 1886, mutta kymmenen vuotta koulun perustamisen jälkeen sukunimi oli kirjattu vasta 20 prosentille kylän ortodoksiperheistä.

Toinen merkittävä syy sukunimien merkitsemiseen ovat ainakin paikoitellen olleet isojako ja sitä seurannut perintökirjojen antaminen eli talonpoikien itsenäistyminen. Salmissa isojako alkoi vuonna 1887 ja päättyi vuonna 1902. Pian isojaon päättymisen jälkeen, vuonna 1905, Salmin Manssilassa ja Uuksalonpäässä sukunimet oli kirjattu noin 80 prosentille ortodoksiperheistä. Koska laskelmassa ovat mukana myös tilattomat, joita isojako ei koskenut, sukunimen saaneiden talonpoikien osuus on vielä suurempi.

Perintökirjan antaminen rajakarjalaiselle talonpojalle ei kuitenkaan ole automaattisesti merkinnyt sitä, että tällä sen jälkeen olisi ollut tai tälle olisi aina kirjattu sukunimi. Esimerkiksi Impilahden Syskyjärvellä jopa joka neljäs ortodoksiperhe on vuoden 1915 
henkikirjassa vielä vailla sukunimeä. Historialliset syyt - isojako ja kansakoulujen perustaminen - selittävät siis vain osan siitä, miksi sukunimiä on alettu kirjata juuri tiettynä ajankohtana.

Tutkimuksessani olen jakanut aineistoni eli Raja-Karjalan ortodoksiväestön sukunimet kymmeneen ryhmään. Ryhmät ovat: venäjänkielisistä patronyymeistä kehittyneet sukunimet (Ivanoff, Siilin), muun muassa venäläisen porvariston venäläiset sukunimet (Gagarin), talonnimistä kehittyneet ristimänimen sisältävät ortodoksitalonpoikien sukunimet (Happo, Patronen), lisänimistä kehittyneet sukunimet (Havanskoi, Kupsa), ortodoksipapiston ja muiden kirkonpalvelijoiden sukunimet (Solntsev), itäsuomalaiset -nen-loppuiset sukunimet (Tossavainen), sattumanvaraisesti otetut tai annetut, savolaisia sukunimiä muistuttavat sukunimet (Pennanen), niin sanotut Virtanen-, Laine-tyypin sukunimet (Salminen, Kivi), ei-ristimänimipohjaisista talon- ja kylännimistä kehittyneet sukunimet (Kivijärvi, Ojatalo) ja ennen 1930-luvun joukkonimenmuuttoja otetut ja suomalaistetut sukunimet (Aarnio, Taulamo).

Tutkimukseni osoittaa, että suurin osa rajakarjalaisista sukunimistä on kehittynyt lisänimistä. Suojärvellä ja Salmissa niiden osuus on noin 50 prosenttia. Tällaisia nimiä on $1800-l u v u l l a$ julkaistuissa sanomalehtikirjoituksissa nimitetty haukkumanimiksi, joita virkamiehet ovat aikoinaan kirjanneet asiakirjoihin. Lisänimistä kehittyneet sukunimet ovat voineet alun perin olla nimettävän ammatista kertovia lisänimiä, esimerkiksi Tschikkuri eli 'räätäli', tai nimettävän syntyperästä kertovia lisänimiä, esimerkiksi Ruotsi, jossa ruottši tarkoittaa 'suomalaista, luterilaista'. Suurin osa tähän ryhmään kuuluvista sukunimistä pohjaa kuitenkin sellaisiin lisänimiin, jotka jollain tavoin kuvaavat nimettävää, tavallisesti tämän käyttäytymistä tai ulkonäköä. Näitä sukunimiä ovat esimerkiksi Bräyschy ja Kotta, jotka voi yhdistää karjalan kielen sanoihin bräyseä eli 'puhua joutavia' ja kotta eli 'kenkäraja' tai kottujalgu eli 'kerjäläinen'. Tämäntyyppisten sukunimien taustalla oleville lisänimille on tyypillistä, että ne ovat luonteeltaan deskriptiivisiä ja nimenantoon ovat voineet vaikuttaa yhtä aikaa useat eri seikat. Esimerkiksi nimille Löttö, Töppönen, Mämmi ja Putro (karjalan 'puuro') on vaikea jälkikäteen osoittaa vain yhtä nimenantoperustetta.

Monia lisänimiä tai niihin pohjaavia sukunimiä on muodostettu myös mallin mukaan. Tällaisia ovat erityisesti nimet, joihin sisältyy jokin eläimen, linnun tai kalan nimitys. Salmissa eräälle sukunimeä Karhu käyttäneen miehen naapurille on annettu nimi Kontio (Salmin Oritselkä 188o) ja Suojärvellä eräässä kylässä on tunnettu nimet Jänis, Repo, Närhi, Kyyhky ja Haukka (Salmin/Suojärven Hyrsylä 1845). Lisänimestä kehittyneistä sukunimistä ei tiedetä, kuka nimet on keksinyt: ei siis tiedetä, pohjaavatko kyseiset sukunimet kyläyhteisön antamiin todellisiin nimiin, joilla henkilöt on tunnettu, vai ovatko ne jonkun virkamiehen keksimiä nimiä. Joka tapauksessa suurin osa rajakarjalaisten lisänimipohjaisista sukunimistä on tulkittavissa nimenomaan karjalan kielen sanaston pohjalta.

Tutkimuksessani olen laatinut etymologian yli 400 lisänimipohjaiselle sukunimelle. Sukunimiä, jotka ovat kehittyneet talonnimestä ja joihin sisältyy venäläisen ristimänimen karjalainen variantti, on laatimassani Nimihakemistossa 256. Nämä lisänimistä ja tietyntyyppisistä talonnimistä kehittyneet sukunimet ovat rajakarjalaisen sukunimistön omaperäistä ydintä. 
Rajakarjalaisilla oli myös sukunimiä, jotka olivat samanasuisia kuin Raja-Karjalan ulkopuolella tunnetut, pääosin itäsuomalaiset sukunimet. Tällaisten nimien esiintyminen Raja-Karjalan ortodokseilla selittyy osittain Pohjois-Karjalan ortodoksien muuttoliikkeellä ja ortodoksien ja luterilaisten seka-avioliitoilla. Kuitenkin osa ortodoksikarjalaisten savolaisia sukunimiä muistuttavista sukunimistä on otettu tai annettu Raja-Karjalassa sattumanvaraisesti. Näiden nimien tutkiminen vaatii kokonaisten sukujen selvittämistä. Esimerkiksi Salmissa sukunimeä Pakkanen käyttäneestä kahdesta ortodoksisuvusta tiedetään, että niiden ainoa yhteys luterilaiseen, samanasuista nimeä käyttäneeseen sukuun on kyseinen sukunimi (Pakkanen 1998: alkusanat).

Tutkimukseni osoittaa, että Raja-Karjalan ortodoksiväestö sai sukunimet sitä mukaa, kun sitä sidottiin osaksi muuta Suomen kansaa. Samaan aikaan rajakarjalainen kulttuuri-identiteetti suomalaistui ja suomen kielen asema Raja-Karjalassa vahvistui entisestään. Tutkimukseni osoittaa myös, että rajakarjalaisten sukunimien muuttaminen myöhemmin eli 1930-luvulla oli osa laajaa, jo aiemmin käynnistynyttä kulttuurin muutosta. Nimistöä, joka oli kehittynyt Raja-Karjalassa, alettiin pitää vanhakantaisena ja venäläisenä eikä sitä tai sen omaperäisyyttä nähty säilyttämisen arvoiseksi.

\section{Lähteet}

E. V. Ahtian aineisto. Laatikko 12. Karjalan sanakirjan arkisto.

HÄMYNEN, TAPIO 2011: "Suomea ne puhui, mutta kyllä ne ryssiä olivat" - ortodoksiskarjalaisen kulttuurin murros Suomessa 1944-2009. - Yury Shikalov, Jukka Kokkonen, Tapio Hämynen \& Aleksandr Pashkov (toim.), Rajalla halkaistu kansa. Karjalaisten kansallisidentiteetin, uskonnon ja kielen kehitys 180o-luvun alusta nykypäiviin s. 203-225. Joensuu: Itä-Suomen yliopisto; Petrozavodsk: Izdatel'stvo PetrGU.

Jeskanen, Matt t 2005: Karjalan kieli ja karjalankieliset Suomessa. - Marjatta Palander \& Anne-Maria Nupponen (toim.), Monenlaiset karjalaiset. Suomen karjalaisten kielellinen identiteetti s. 215-285. Studia Carelica Humanistica 20. Joensuu: Joensuun yliopisto.

Koккоnen, Jukка 2015: Johdanto. - Jukka Kokkonen (toim.), Rajoil da randamil. Salmi ja salmilaiset 1617-1948 s. 15-24. Saarijärvi: Salmi-Säätiö.

LAMPÉn, ERnst 1922: Pika-kuvia Raja-Karjalasta. Helsinki: Otava.

Lehtola, Veli-PekKA 2012: Saamelaiset suomalaiset. Kohtaamisia 1896-1953. Helsinki: Suomalaisen Kirjallisuuden Seura.

LESKINEN, EıNO 1931: Karjalan kieli maamme rajojen sisäpuolella. - Suomen Heimo 1/1931 S. 8-9.

MаккоNen, Hегккі 1989: Kuolema ortodoksisessa perinteessä. Joensuun yliopiston teologisia julkaisuja n:o 1. Joensuu: Joensuun yliopisto.

Pakkanen, Veli-Pek a 1998: Salmin Pakkaset. Jyväskylä: Pakkasen sukuseura.

Raivo, Petri 1996: Maiseman kulttuurinen transformaatio. Ortodoksinen kirkko suomalaisessa kulttuurimaisemassa. Nordia Geographical Publications Vol. 25:1. Oulu: Oulun yliopisto.

SKS KIA: Ahtia = E. V. Ahtian arkisto: Ba Saapuneet kirjeet ja Kirjekokoelma 234. Suomalaisen Kirjallisuuden Seuran Kirjallisuusarkisto. 
Outi Patronen: Rajakarjalaisen sukunimistön kehittyminen osana Suomen karjalankielisen ortodoksivähemmistön suomalaistumista 1818-1925. Helsinki: Helsingin yliopiston suomen kielen, suomalais-ugrilaisten ja pohjoismaisten kielten ja kirjallisuuksien laitos 2017. Kirja on luettavissa osoitteessa https://helda.helsinki.fi/handle/10138/224298.

Kirjoittajan yhteystiedot:

etunimi.sukunimi@gmail.com 